\title{
Simultaneous Occurrence of Two Rare Diseases: Actinomycosis and Melanoma of the Rectum
}

\author{
Eugen Dumitru', Irina Magdalena Dumitru' ${ }^{1}$, Razvan Popescu' ${ }^{1}$, Ghiulendan Resul' ${ }^{2}$, Ionut Bulbuc ${ }^{1}$, Sorin Rugina ${ }^{1}$
}

1) Ovidius University;

2) Clinical Infectious

Diseases Hospital

Constanta, Romania

\author{
Address for correspondence: \\ Eugen Dumitru \\ Ovidius University of \\ Constanta \\ George Enescu Str. 23 \\ Constanta, Romania \\ eugen.dumitru@yahoo.com
}

Accepted: 13.12.2013

\begin{abstract}
The simultaneous occurrence of two rare conditions in a single patient is uncommon. We report the case of a patient with rectal actinomycosis covering an anorectal melanoma (both infrequent conditions), the last one being later recognized, only after surgical excision. We underline here the role of thinking "outside the box" when an unusual situation is experienced.
\end{abstract}

Key words: rectal actinomycosis - anorectal melanoma - rectal surgery.

\section{INTRODUCTION}

Anorectal melanoma is a rare condition with a poor prognosis. Diagnosis is often revealed postoperatively [14]. Actinomyces israelii is a commensual germ, which in rare cases can cause a chronic infection mimicking a malignant tumor with various locations [5]. We present a case of actinomycosis associated with an anorectal melanoma.

\section{CASE \\ PRESENTATION}

A 60-year-old female patient with no relevant past medical history was admitted in our hospital for constipation, fever, decreased appetite and weight loss, symptoms that had appeared gradually over the last three months. Physical examination gave no significant information. Rectal tact revealed a tumor solid and irregular, situated immediately above the anorectal line. We performed a colonoscopy that showed a tumoral mass (diameter $40 \mathrm{~mm}$ ) in the rectum with polypoid appearance and wide implantation base, which infiltrated the mucosa, with a firm consistency and irregular surface covered with mucus and fibrino-necrotic tissue and without intestinal luminal obstruction but involving the anorectal line (Fig.1). The endoscopic diagnosis was of a rectal tumor involving the anorectal border. Tumor biopsies were performed, and microscopic examination revealed the presence of nonkeratinized squamous epithelium with acanthosis, koilocytes, focal intraepidermal lysis accompanied by neutrophilic inflammation, and absence of malignancy; tissue fragments sampled from the squamo-columnar junction showed active nonspecific granulomatous inflammation, suppurative necrosis and colonies of $A$. israelii (Figs. 2, 3).

All the laboratory tests were normal, including CA19-9 and CEA.

A native and postcontrast pelvic MRI examination revealed an exophytic rectal tumoral mass, with discrete hypersemnal T2, T1 and heterogeneous gadolinophilia, 45x46x44 mm in size, situated in the pelvic-perineal rectum with invasion of the left anterolateral fibrous layer, extension into the perirectal fat without boundary demarcation to the recto-vaginal fascia. Pelvic lymphadenopathies were visualized, with a maximum size of $13 \mathrm{~mm}$ in axial diameter (Fig. 4).

Although anorectal actinomycosis is rare in clinical practice, this chronic infection may progress into an abscess with infiltration of adjacent structures, thus mimicking a tumor. It was decided to start antibiotic treatment and closely monitor the evolution. The patient was referred to the Infectious Diseases department where intravenous penicillin, $18 \mathrm{MIU} /$ day for three weeks, was administered. Five days after the beginning of treatment, the patient became afebrile, the 
appetite recovered, but the bowel transit disorder persisted, and after three weeks of therapy, the colonoscopy was repeated.

This second examination showed the same protrusive tumoral mass in the rectum but diminished in size $(25 \mathrm{~mm})$, and biopsies from the tumor were sampled again. Microscopic examination of the biopsy samples revealed acute inflammation with an abscess formed in the rectal mucosa, the presence of microorganisms consistent with Actinomyces spp., and absence of any malignancy.

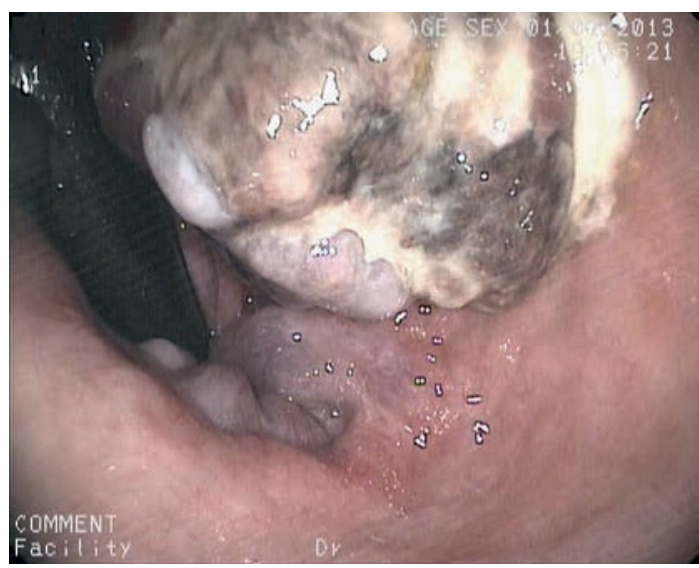

Fig. 1. Colonoscopy image showing a tumoral mass in the rectum with polypoid appearance and wide implantation base, surface covered with mucus and fibrino-necrotic tissue.

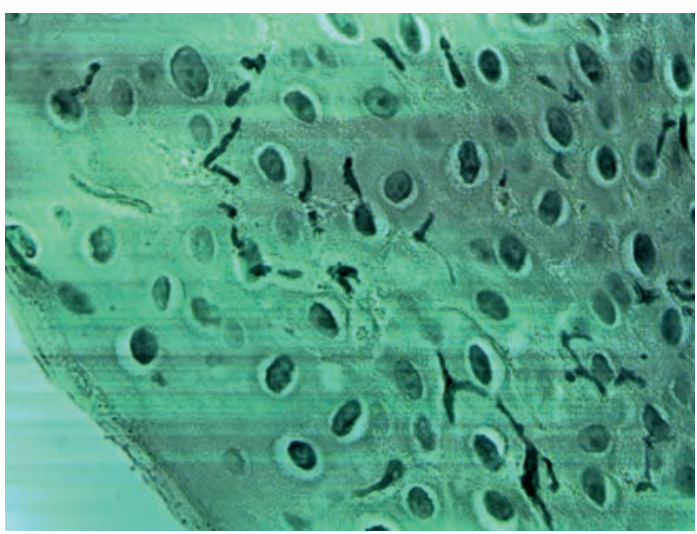

Fig. 2. Stratified squamous epithelium of anal mucosa colonised by short filamentous microorganisms of Actinomyces Spp, some of them with right-angle branching (Van Gieson stain x 400).

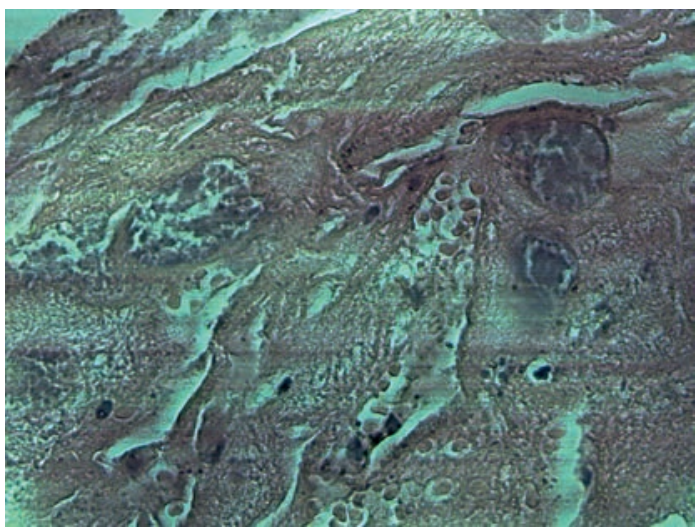

Fig. 3. Actinomyces colonies presenting as „sulfur granules" (H\&E x 400).

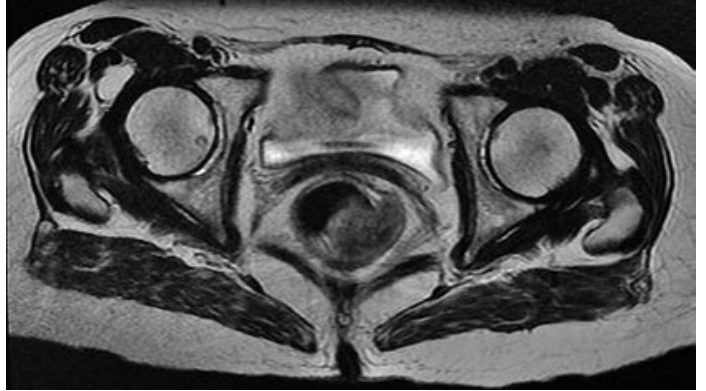

Fig. 4. MRI examination showing an exophytic rectal tumoral mass with invasion of the left anterolateral wall and extension into the perirectal fat.

The treatment was continued with oral penicillin for another three weeks.

The patient continued to complain of anorectal discomfort and constipation after this period, so that a surgical intervention was scheduled. Transanal resection of the tumor with partial excision of the anorectal wall was performed, with hemostasis and mucocutaneous plasty under spinal anesthesia. The morphopathological examination of the surgically removed sample revealed lesions of malignant melanoma in the vertical growth phase, invasive into the anorectal wall, ulceration of the superficial rectal and anal epithelium, vascular and neural invasion, and extensive areas of tumoral necrosis (Fig. 5).

After the malignant melanoma was diagnosed, a PET-CT was performed, which indicated a high metabolic activity in the rectal wall with extension to the posterior vaginal wall, to the perirectal fat, regional adenopathies and bone lytic lesions of the spine and pelvis (Fig. 6).

The patient was referred to the Oncology department for specific treatment and monitoring.

\section{DISCUSSION}

Actinomycosis is a rare infection in humans, which is characterized by abscess formation, tissue fibrosis, sulfur granules in the lesions, and the formation of draining sinuses. Actinomycosis is most frequently caused by $A$. israelii and is sometimes known as the "most misdiagnosed disease” as it is frequently confused with neoplasms [5]. The disease may be localized or extensively spread without confining to fascial and

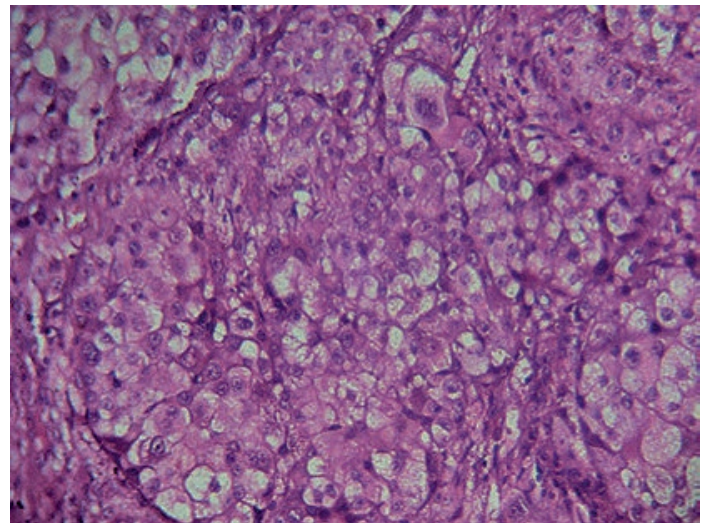

Fig. 5. Malignant melanocytic cells with anisocaria and granular cromatin (H\&E x 400). 


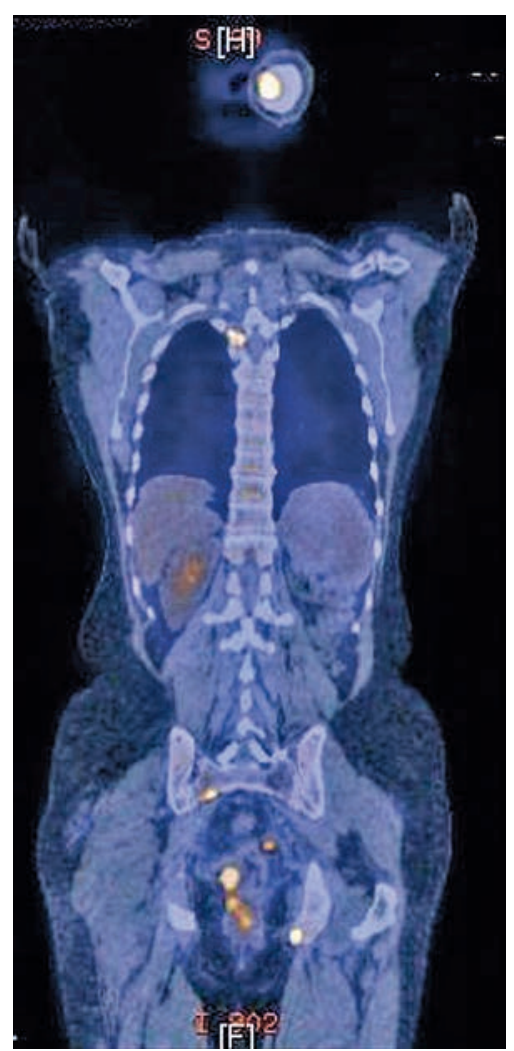

Fig. 6. PET-CT: bone lytic lesions of the spine and pelvis.

connective tissue planes or vascular channels. Gastrointestinal actinomycosis usually presents as a slow-growing mass, caused by the penetration of Actinomyces through the intestinal wall.

When localized in the gut, actinomycosis has a predilection for the ileocecal region. This type of actinomycosis may be misdiagnosed as Crohn's disease, malignancy, intestinal tuberculosis, amebiasis, chronic appendicitis, or carcinoma of the cecum [6, 7]. Other common locations are the stomach, prepyloric area and the sigmoid colon, but almost every other region of the intestine might be involved [8]. Anorectal disease is common, and may present as rectal stricture, perirectal or ischiorectal abscess, or recurrent draining sinuses and fistulae [9]. The primary site may be an anal crypt, or there may be direct extension from an intra-abdominal infection [10].

Actinomycosis may be difficult to diagnose at the onset. If suspected, Actinomyces may be isolated in pus or tissue specimens by laboratory tests.

Actinomycosis usually occurs in immunocompetent persons but may also occur in patients with diminished host defenses. As saprophytes, Actinomyces species have usually a low pathogenicity and develop the disease only in the case of prior tissue injury [11]. To date, no cases of actinomycosis associated with a gastrointestinal malignant tumor have been documented.

The primary anorectal melanoma is a tumor with origin in the melanocytes of the mucosa of the anal canal, and has a low occurrence rate $(0.4 \%-3 \%$ of all malignant melanomas and $0.1 \%-4.6 \%$ of all malignant anorectal tumors), being the third most frequently affected region by melanoma after the skin and the retina [1-4]. It has a poor prognosis and a limited survival (10\% at 5 years) [12]. Initial misdiagnosis may occur in $80 \%$ of the cases [13-15].

The differential diagnosis should be made between a primary anal melanoma and cutaneous metastases of a malignant melanoma, and it is based on a thorough clinical examination. In this particular patient, clinical examination did not reveal any suspicious lesions. The association between cancer and actinomycosis has been rarely described. In fact, the only presentation belongs to Grisaru et al, who described two cases of vaginal actinomycosis associated with vaginal squamous cell carcinoma and malignant melanoma [16]. To the best of our knowledge, the case we described here is the first case of actinomycosis associated with anorectal malignant melanoma.

This association may have a common immunological or microbiological underlying factor or could be coincidental for the two diseases with low prevalence.

\section{CONCLUSION}

In spite of the low prevalence of anorectal melanoma and of intestinal actinomycosis, the occurrence of both these conditions in one patient should raise the awareness of clinicians to consider this possibility in patients with anorectal actinomycosis.

Conflicts of interests: None to declare.

\section{REFERENCES}

1. Thibault C, Sagar P, Nivatvongs S, Ilstrup DM, Wolff BG. Anorectal melanoma: an incurable disease? Dis Colon Rectum 1997;40:661668.

2. Chang AE, Karnell LH, Menck HR. The National Cancer Data Base report on cutaneous and noncutaneous melanoma: a summary of 84,836 cases from the past decade. The American College of Surgeons Commission on Cancer and the American Cancer Society. Cancer 1998;83:1664-1678.

3. Heyn J, Placzek M, Ozimek A, Baumgaertner AK, Siebeck M, Volkenandt M. Malignant melanoma of the anal region. Clin Exp Dermatol 2007;32:603-607.

4. Klas JV, Rothenberger DA, Wong WD, Madoff RD. Malignant tumors of the anal canal: the spectrum of disease, treatment, and outcomes. Cancer 1999;85:1686-1693.

5. Koren R, Dekel Y, Ramadan E, Veltman V, Dreznik Z. Periappendiceal actinomycosis mimicking malignancy report of a case. Pathol Res Pract 2002;198:441-443.

6. Goldman L, Ausiello D. Actinomycosis. Cecil Medicine. 24th ed Philadelphia, Pa: Saunders Elsevier, 2011.

7. Richards RJ, Grayer D. Actinomycosis: a rare cause of vesicocolic fistula Am J Gastroenterol 1989;84:677-679.

8. de Feiter PW, Soeters PB. Gastrointestinal actinomycosis: an unusual presentation with obstructive uropathy: report of a case and review of the literature. Dis Colon Rectum 2001;44:1521-1525.

9. Filippou D, Psimitis I, Zizi D, Rizos S. A rare case of ascending colon actinomycosis mimicking cancer. BMC Gastroenterol 2005;5:1.

10. Harris LA, DeCosse JJ, Dannenberg A. Abdominal actinomycosis: evaluation by computed tomography. Am J Gastroenterol 1989;84:198200. 
11. Smego RA Jr, Foglia G. Actinomycosis. Clin Infect Dis 1998;26:12551261.

12. Solaz Moreno E, Vallalta Morales M, Silla Búrdalo G, Cervera Miguel JI, Díaz Beveridge R, Rayón Martín JM. Primary melanoma of the rectum: an infrequent neoplasia with an atypical presentation. Clin Transl Oncol 2005;7:171-173.

13. Das G, Gupta S, Shukla PJ, Jagannath P. Anorectal melanoma: a large clinicopathologic study from India. Int Surg 2003;88:21-24.
14. Maqbool A, Lintner R, Bokhari A, Habib T, Rahman I, Rao BK. Anorectal melanoma - 3 case reports and a review of the literature. Cutis 2004;73:409-413.

15. Morson BC, Volkstadt H. Malignant melanoma of the anal canal. J Clin Pathol 1963;16:126-132.

16. Grisaru D, Raz Y, Shtabsky A. A peculiar presentation: for 2 women, a rare infection preceded a more urgent diagnosis. Am J Obstet Gynecol 2012;207:342.e1-2. 